\title{
تأثير اللون والضوء على الفراغات السكنية الداخلية
}

م/ ريم محمد أشرف البثكار

بكالوريوس الهندسة المعمارية البئية

جامعة المنصورة المعمارة

\author{
أ.د/ شهيرة سيد شرف الدين د د/عزة صبحي السقا \\ جامعة طنطا
}

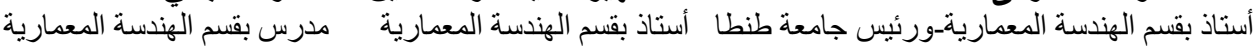

أستاذ بقسم الهندسة أحمد زكى أمعمار جامعة طنطا
سطح معين بأطو ال موجية مختلفة مما يجعل العين تميز بين لون وآخر وسطح

و وآخر [2] .

خصائص اللون [3] :

-صفة اللونHue مuت : تعرف بالصفة التي يسمي بها اللون .

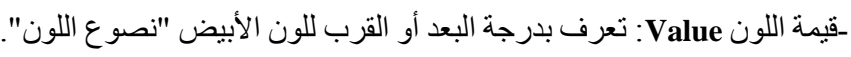

الإشباعSaturation:يعرف بدسامة الذرات اللونية بالمساحة " نقاء اللون " .

2-2-1

هي مجمو عة من الألوان (12لون) بنظام دقيق متجانس ومتساوي صممت من

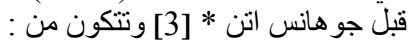

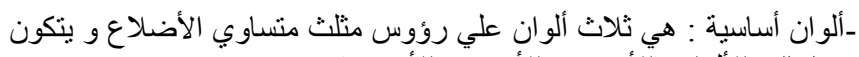

منها باقي الألوان (ألأزرق و الألان الحمر و الأصفر ).

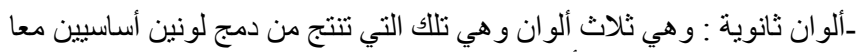

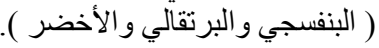



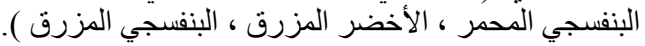

3-2-1 تصنيفات الألوان حسب درجة الحرارة للون

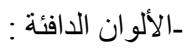

وتثمل ( الأحمر،الأصفر، الذهبي ، البني ، المخملي).

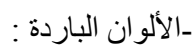

(الفيروزي ، الأخضر ، الأزرق ، الأخضر المائل للصفرة).

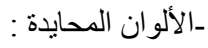

( الأبيض، الرمادي ، الفضي ، البني ، البيج ، الأسود).

3-1



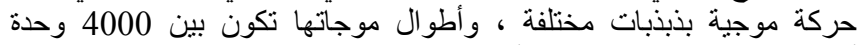

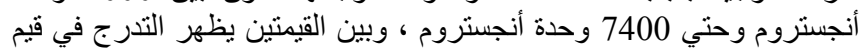

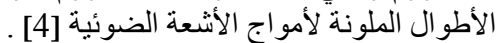

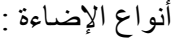

الإضـاءة الطبيعية : و هي التي تعتمد علي الثمس و أثتعتها المباشرة و الغير مباثرة

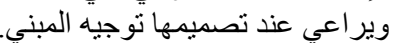

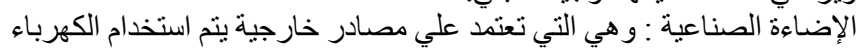
أو الغاز للحصول علي الضوء الضي الضي .

\section{1-3-1 المظهر اللوني للمصابيح واللون المستخلص}





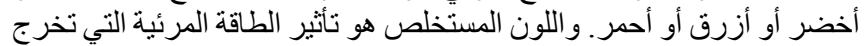

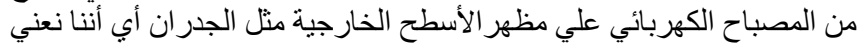

الملنص- إن اللون و الضو ء بينهما علاقة ارتباط قوية تتضح من خلال البيئة

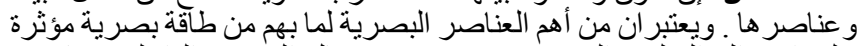

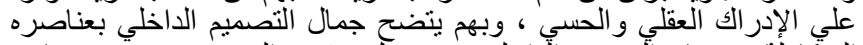

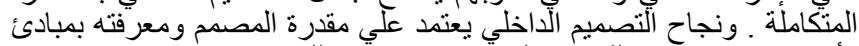

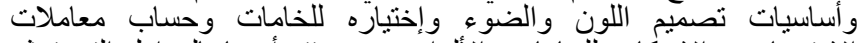

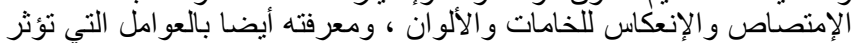

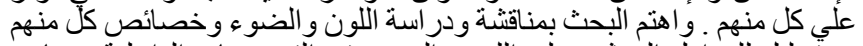

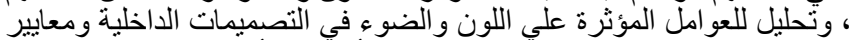

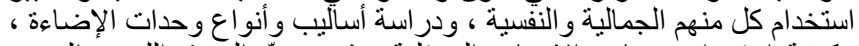

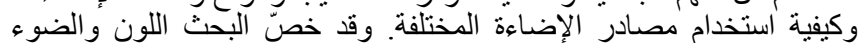

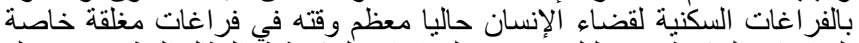

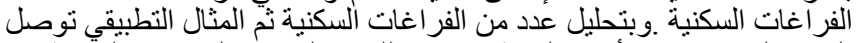

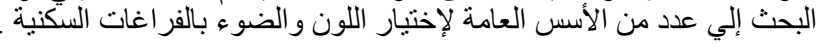

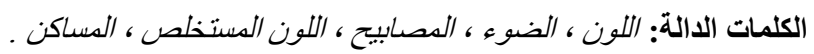

المقدمة

يتطلب التصميم الجيد للون والضوء ولئه في الفراغات الداخلية للمباني السكنية ،

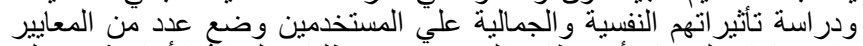

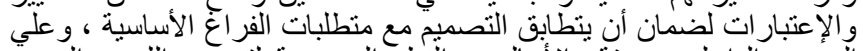

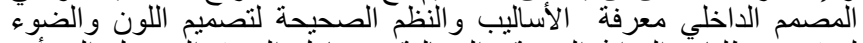

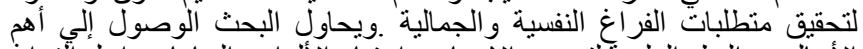

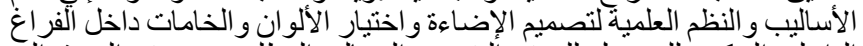

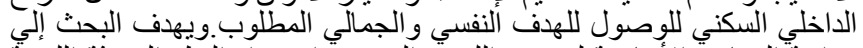



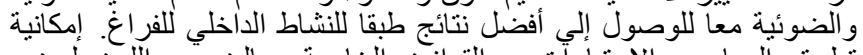

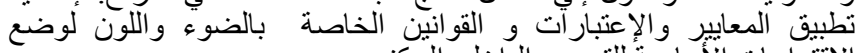

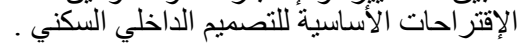

منهجية البحث

لعتمد منهج البحث علي المنهج الإستقر ائي و المنهج التحليلي و المنهج

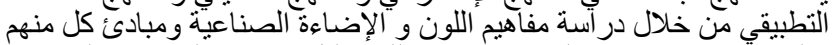

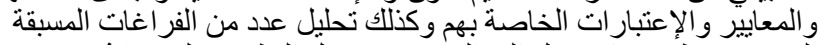

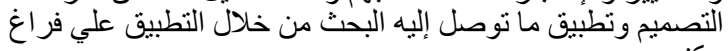
سكني . 1. - الإطار النظري

تناول الإطار النظري شرح بعض المفاهيم الهامة المكونة للبحث وعلافتهاتها

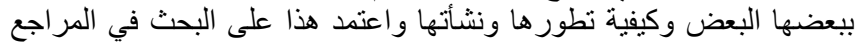
الخاصة بكل مفهوم على حده فيما يلي: -

1-1

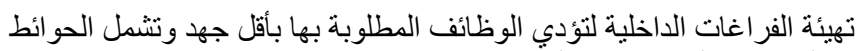

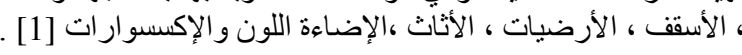

2-1 أهمية التصميم الاخلي

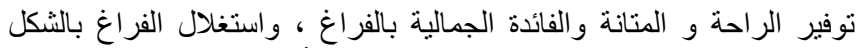

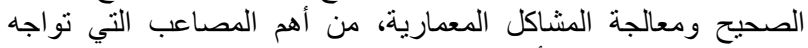
المصدم الداخلي ، مع الأخذ بعين الإعتبارتحقيق النئية الناحية الجمالية و النفسية

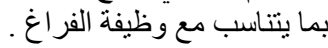

1-2-1 اللون وخصائصه

اللون هو النتأثير الفسيولوجي الذي ينتج عند استقبال العين للضوء المنعكس من 
يحاول أن يبحث عن البديل [8] ، ثم استخدم بعد ذلك النار و المشاعل و الثموع

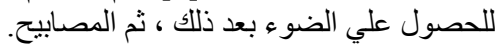

5-3-1 أساسيات الإضاءة الاخلية

لإختيار الإضاءة الصحيحة للفراغ لابد من تحديد استعمالات ونوعية الأنشطة

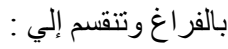

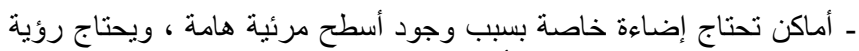

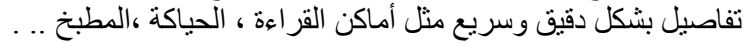

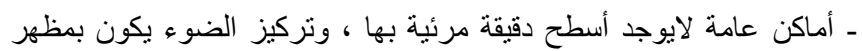

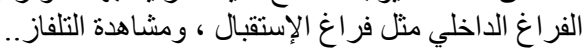

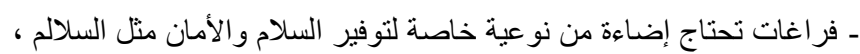

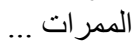

6-3-1

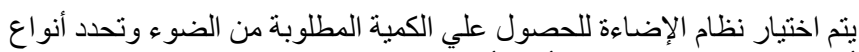
أنظمة الإضـاءة بالمسكن في أربع أقسام :

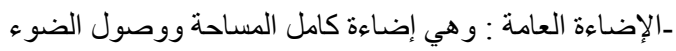

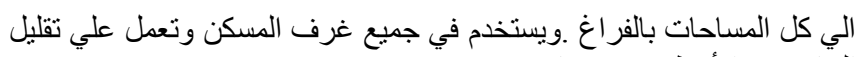

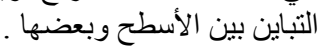
ـالإضاءة الزاوية : تستخدم لتركيز الضوء علي سطح محدد وتنتخدم داخل

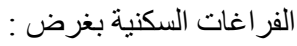

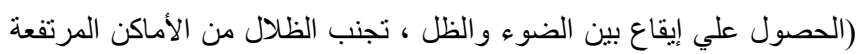
و إظهار مختلف الجو انب الديكورية ). ـالإضـاءة المركزة : تستخدم لتركيز الضوء علي سطح محدد.

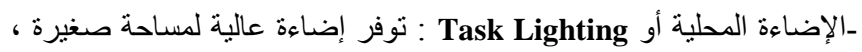

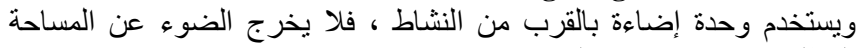
المطلوبة (وحدة إضاءة علي سطح مكتب ) .

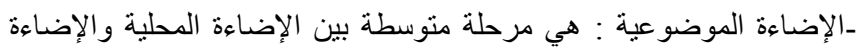

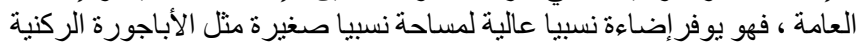
، ويمكن تحريكه و التحكم فيه.

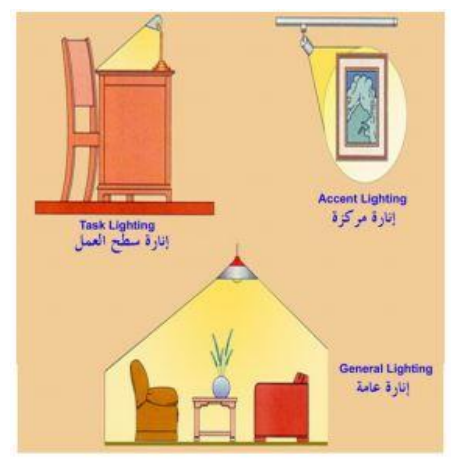

شكل (2) أنظمة الإضاءة الداخلية المصدر

7-3-1 توزيع الأشعة الضوئية يتم توزيع الأشعة الضوئية بأحد الصور التالية :

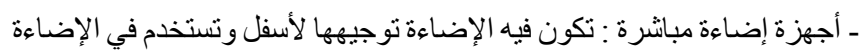
العامة] [9]ة
استخلاص اللون الظاهر عند سقوط طيف المصباح عليها ـ ومنحني اللونية

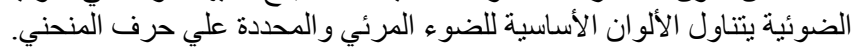

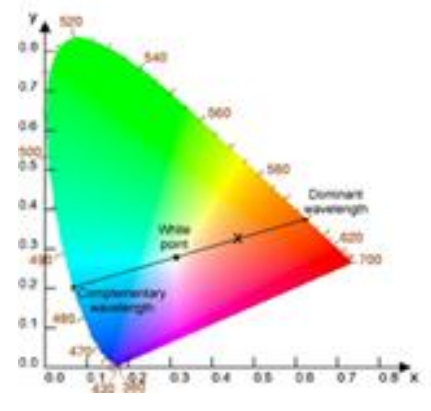

شكل (1) المظهر اللوني للمصابيح

المصدر

و المنحني يغلق عند توصيل خط مستقفيم بداية من نهاية الطيف البنفسجي

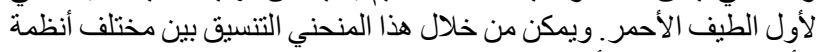
الألوان وتوصيف الألو ان ومعرفة خصنة خلائصها.

2-3-1 أنواع المصابيح المستخدمة بالفراغات السكنية الداخلية ومميزاتها واستخداماتها و العيوب:

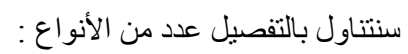

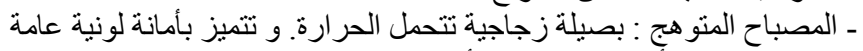

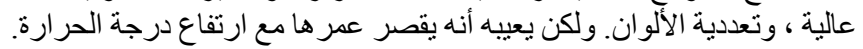

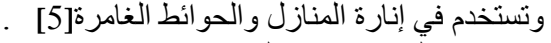

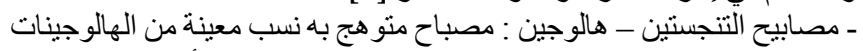

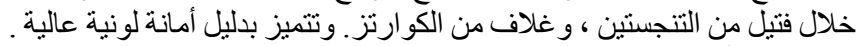

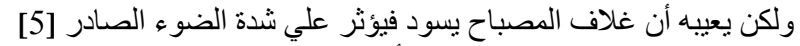

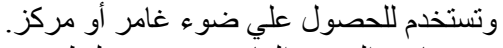

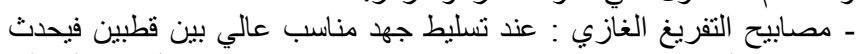

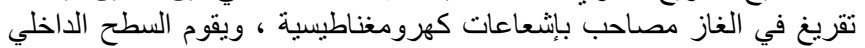

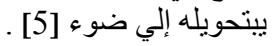
ـ المصابيح الفللورية(الفلورسنت): أنبوبة زبنة جاجية ممتلئة بغاز الأرجون أو النيون

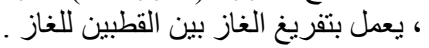

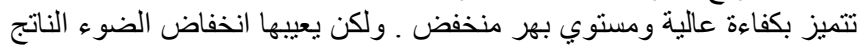

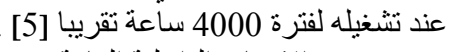
وتستخدم في الإضاءة الداخلية العامة.

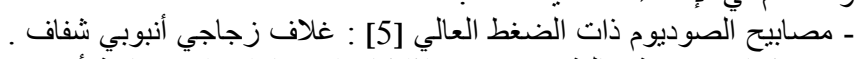

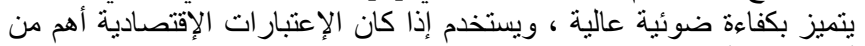

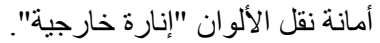

3-3-1 المباني السكنية

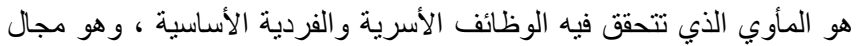

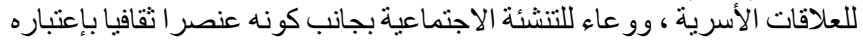

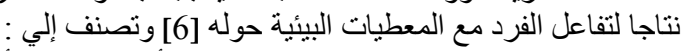

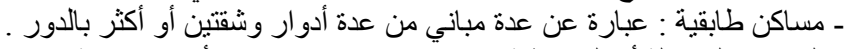

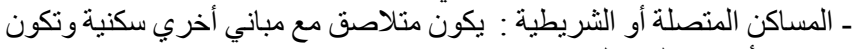

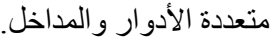
ـ السكن البرجي : انتشر في المدن الندار الكبرى للإستفادة من الأر اضي باهظة الثمن

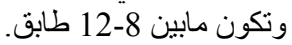

\section{4-3-1 لمحة تاريخية عن تطور الألوان والإضاءة}

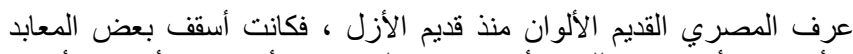

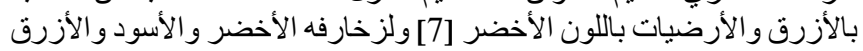

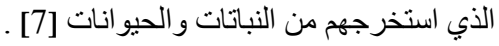

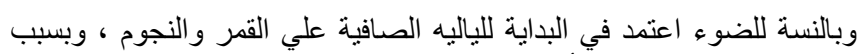
تغيرات الجو من سحب ؤأمطار و غيره كان يختفي ألقمر والنجوم ، مما جعله 
ـالأطباق : هياكل معدنية زجاجية ، تستخدم في الممر ات و غرف النوم وتثبت

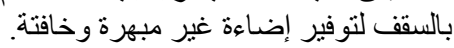

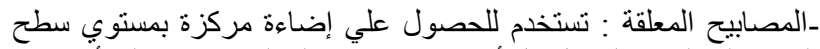

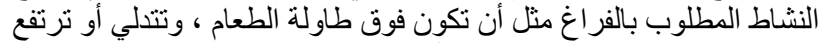

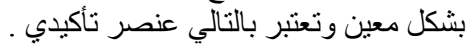

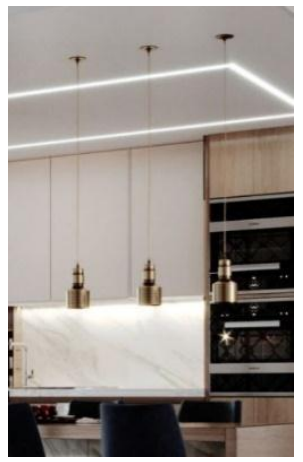

شكل (8) المصابيح المعلقة

)cometarch.com ( مارس م

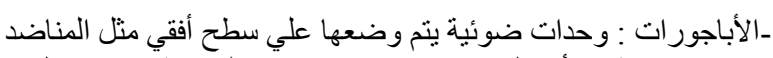

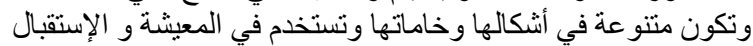

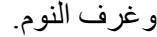

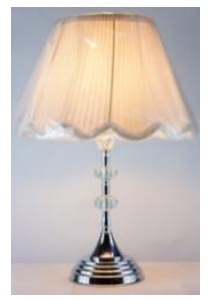

شكل (9) أباجورة ركنية

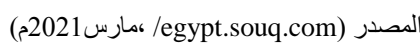

ـالأبليكات : وحدات حائطية تدعم الإضاءة في أماكن مختلفة وتستخدم في

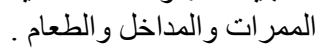

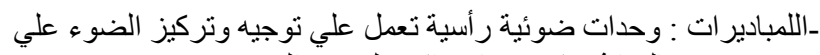



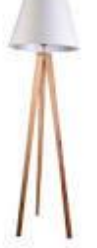

شكل (10) وحدة إضـاءة لمبادير

المصدر ( enarat.com ، مارس 2021م )

الفو انيس : تستخدم في المداخل بأثكال شرقية بزجاج ملون ونتبت علي الحائط أو تتدلي من الَّقف .

9-3-1 طرق وأشكال إضاءة الحوائط السكنية

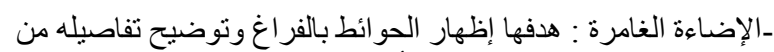

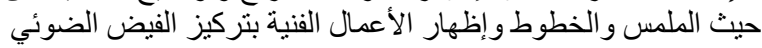

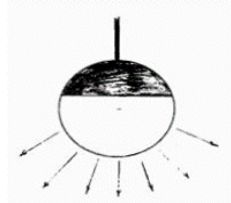

شكل ( 3 ) الإضاءة المباثرة

المصدر

ـأجهزة شبه مباثرة : تتنشر فيها الأشعة في جميع الإتجاهات بنسبة 40\% و 60\% بالسقف و الحو ائط مباشرة .

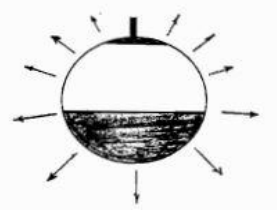

شكل (4) إضاءة شبه مباشرة

المصدر (2002م، عميش ) (10)

ـأجهزة إضاءة منتشرة : وهي تنشر الأشعة الضوئية عامة ، ومشعة في كل

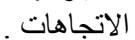

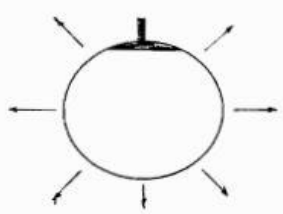

$$
\text { شكل (5) إضاءة منتشرة }
$$

المصدر (2002م، عميش )

ـ أجهزة إضاءة منتشرة وغير مباثرة : تقوم بنشر الأشعة الضوئية علي السقف و الحو ائط بنسبة 90\% ثم تنعكس مرة أخري بالفر اغ.

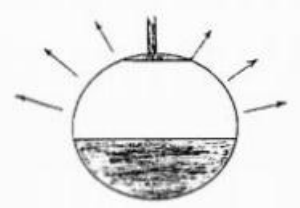

شكل (6) إضاءة منتشرة وغير مباشرة

المصدر (2002م، عميش )

8-3-1 توزيع الأشعة الضوئية

يتم اختيار مصدر الضوء علد علي أساس نقدير نتائج التصميم النهائية و وحدات



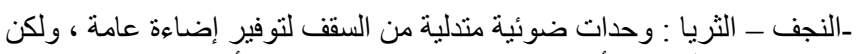

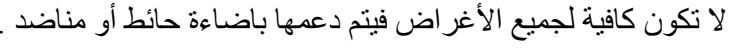

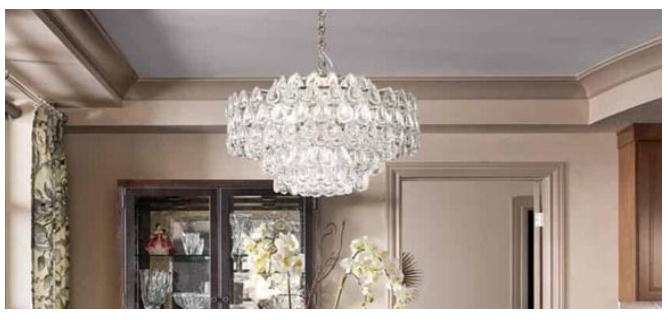

شكل (7) النجف ـ الثريا

المصدر (duetdesigngroup.com ، مارس2021م ) 


\section{0-3-1 أثر استخدام الضوء الصناعي جماليا}

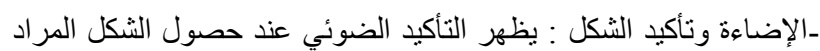

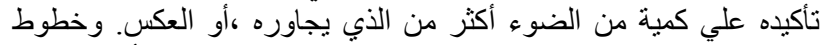

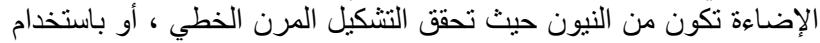

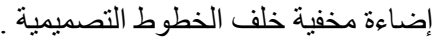

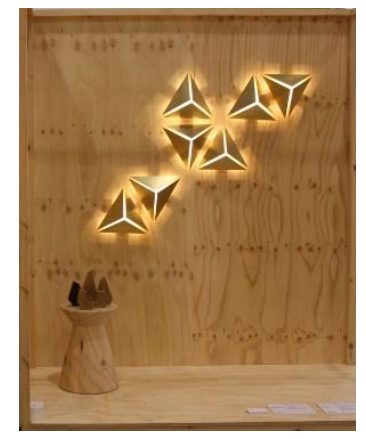

شكل (15) الإضاءة و تأكيد الثكل

المصدر(mocosubmit.com، مارس 2021)

ـالإضاءة وتأكيد خطوط التصميم : يتم الحصول عليه عند تركيز شكل

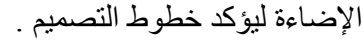

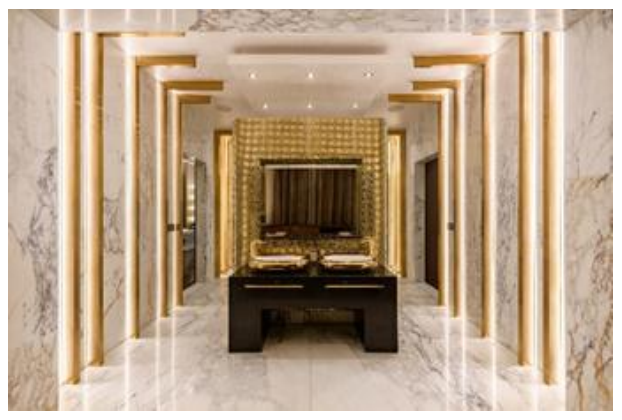

شكل (16) الإضاءة وتأكيد خطوط التصميم

المصدر ( archdaily.com/ ، مارس 2021)

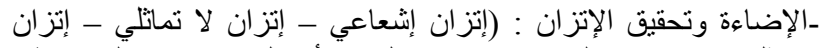

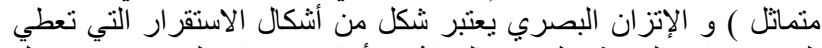





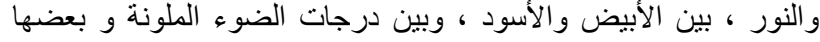

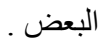

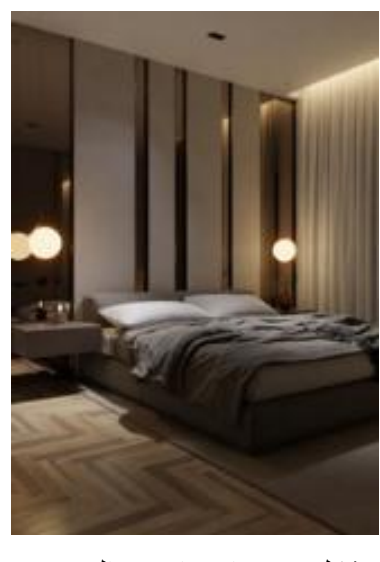

شكل (17) الإتزان في التصميم

المصدر (archdaily.com/ ، مارس 2021م)

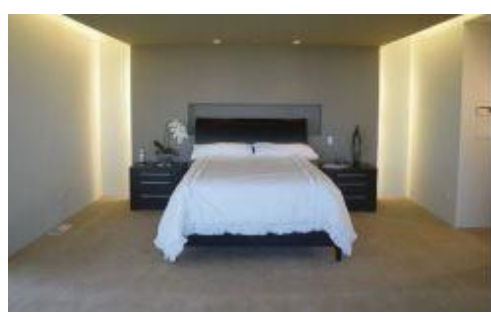

شكل (11) إضاءة غامرة للحو ائط

المصدر (blog.dcorstore.com ، مارس 2021م )

ـالإضـاءة الغامرة الغير متجانسة : تعمل علي الحائط حركة تباينية ضوئية

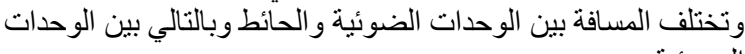
الضوئية .

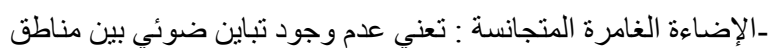

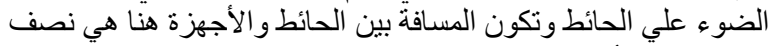

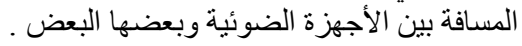

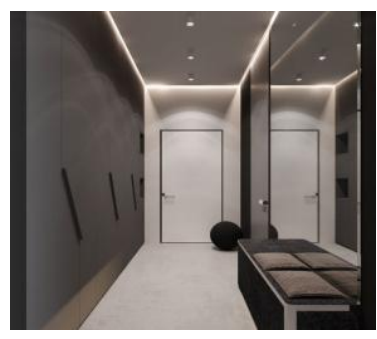

شكل (12) إضاءة غامرة منجانسة للحو ائط

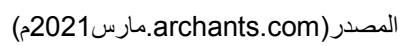

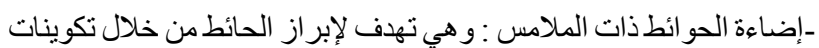

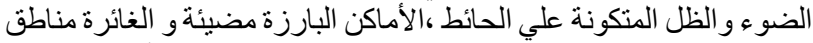

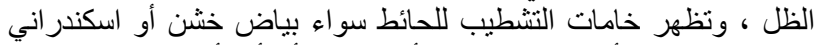
الحمائط المسا الناعم ، أو حجر صناعي أو طبيعي أو أي أعمال جدارية علئ أني

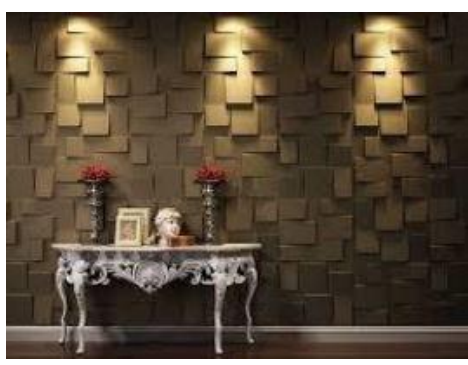

شكل (13) إضاءة الحو ائط ذات الملامس

المصدر(Dihanat-baredh.com،مارسم2021م)

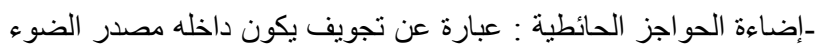

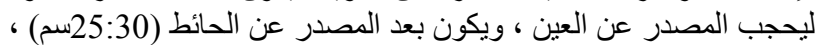
وتكون رأسية أو أفقية أو مائلة.

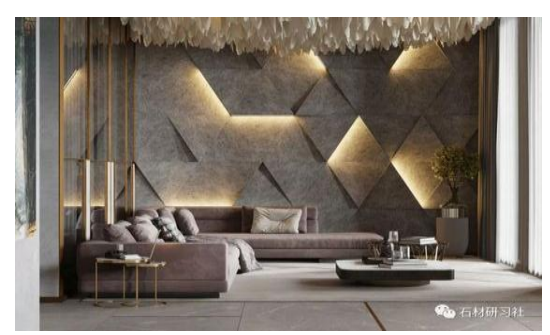

شكل (14) إضاءة الحواجز الحائطية

المصدر( blog.dcorstore.com، مارس 2021) 
الإضاءة الموزعة : تستخدم في المداخل والممر ات الرئيسية وتعط إحساس

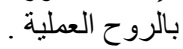

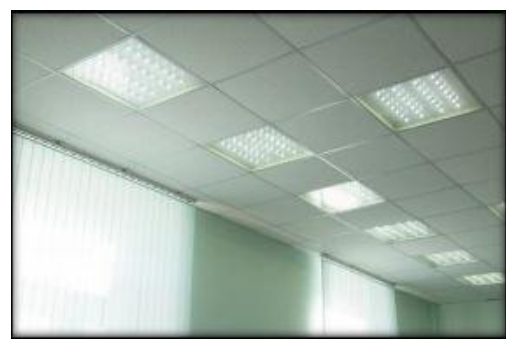

شكل (21) الإضاءة الموزعة

(2018، مدثر)

الإضـاءة الغير مباشرة : تعمل علي زيادة الإحساس بالر احة البصرية

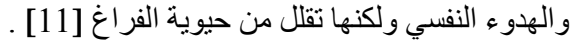

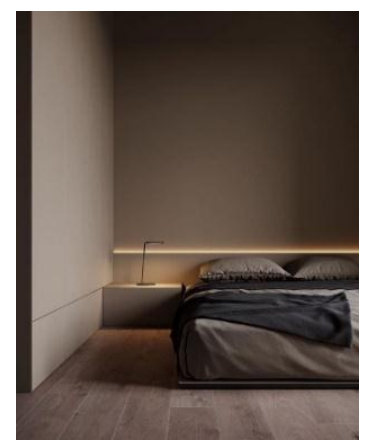

شكل (22) الإضاءة الغير مباشرة

المصدر(theultralinx.com ، مارس 2021م)

12-3-1 أثر استخدام الضوء الصناعي نفسيا

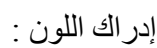

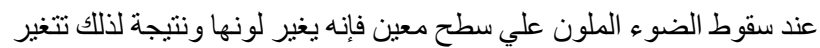

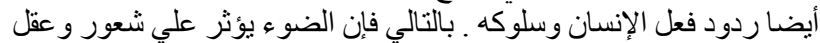



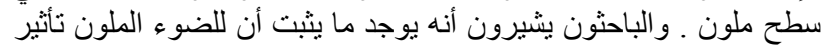

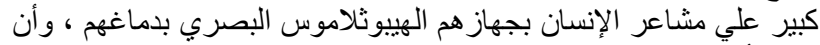

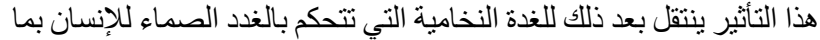

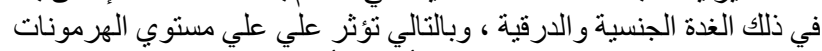

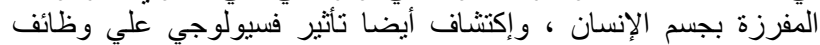

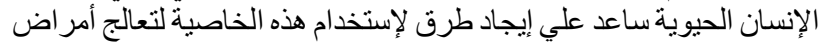
عديدة.

- الإضاءة و التأثثير العاطفي :

يمكن أن يضاء الفر اغ لتحقيق الر احة البصرية ، ولكن التاثير العاطفي الناتج

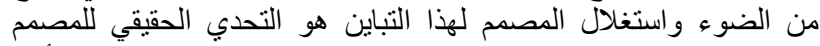

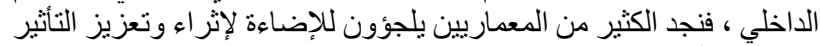

العاطفي ، أو نقل معاني و إيحاءات محددة مثل كاتندر ائية نوتردام لأنرام (5) .



شكل ( 23 ) لقطات داخلية لكاتدر ائية نوتردام بفرنسا

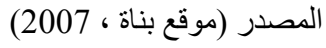

$$
\text { ـالإضاءة والإيقاع في التصميم : }
$$

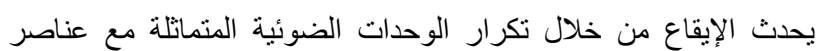

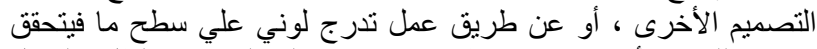

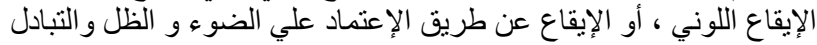

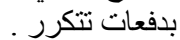

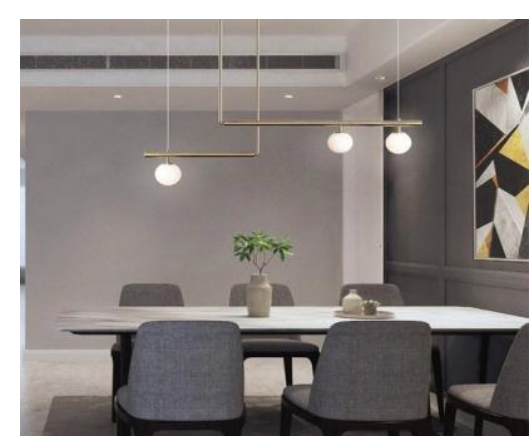

شكل (18) الإيقاع في التصميم

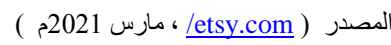

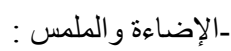

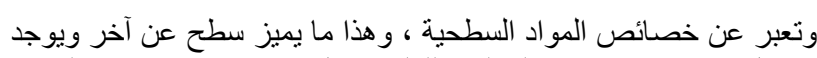

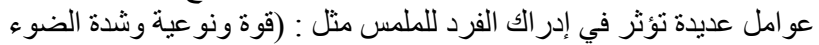

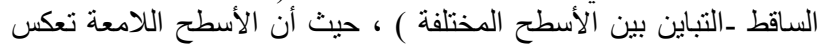

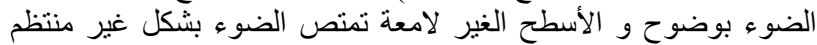
وتظهر ببريق أقلى .

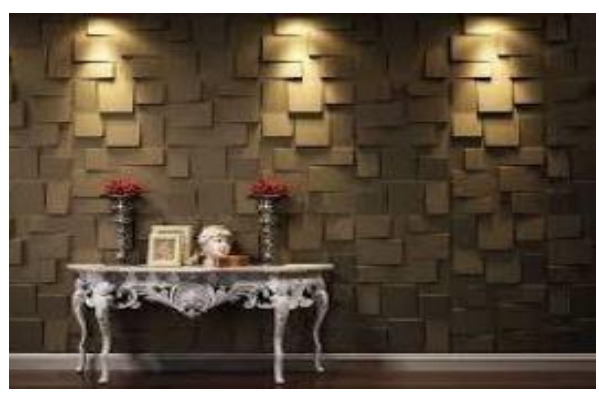

شكل (19) الإضاءة وتوضيح تفاصيل ملمس السطح

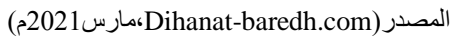

11-3-1 توزيع الأشعة الضوئية

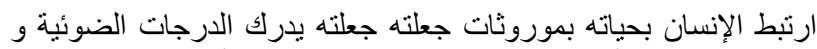

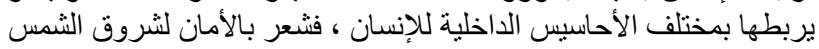
وشعر بالخوف عندما حل الظلام .

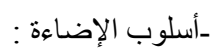

الإضـاءة المباثرة : تجذب الإنتباه لعناصر الفراغ جميعها وتزيد من التركيز

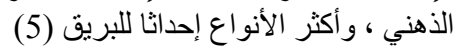

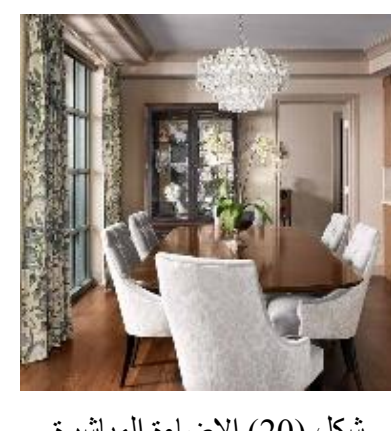

شكل (20) الإضـاءة المباشرة

المصدر (duetdesigngroup.com ، مارس 2021م) 
ـنظام الألوان المكملة Complementary: دائرة الألوان وألكثر المخططات إنز انا.



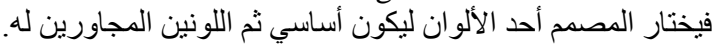



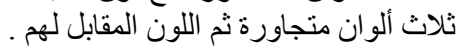
-خطة الألوان الثلاثية Traid: عبارة عن ثلاث ألوان يقعو علي رؤوس

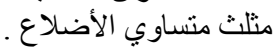

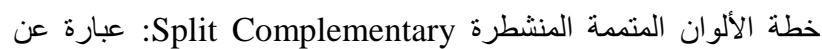
ثلاث ألوان ، لون مع اللونين المجاورين للون المقابل مما يخلق حرف عان مضموم. خطة الألوان الرباعية Square: أربعة ألو ان يكونان مربع ، وبين كل لون

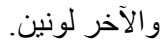



MONOCHROMATIC

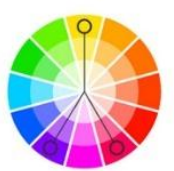

SPLIT COMPLEMENTARY

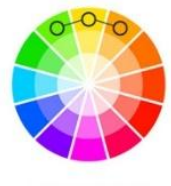

ANALOGOUS

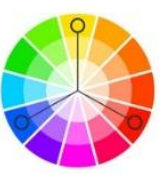

TRIAD

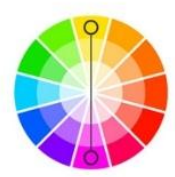

COMPLEMENTARY

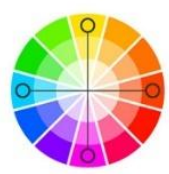

SQUARE
شكل (25) الخطط اللونية التي تحقق الإنسجام اللوني

المصدر (moving.com/ ، مارس 2021م)

-جذب الإنتباه و التأكبد اللوني :

تعمل الألوان الساخنة علي جذب الإنتباه حيث أنها ظاهريا قريبة للعين بينما الألوان الباردة تظهر متأخرة عن العين .

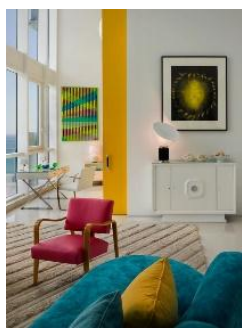

شكل (26) صورة توضح جذب الإنتباه للون الأصفر

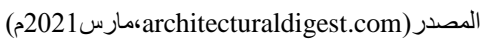

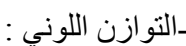

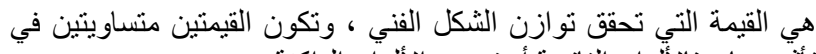

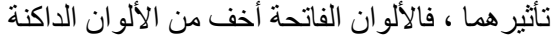

: 4-4-1 أثر استخدام اللون نفسبيا

فلسفة اللون : العديد من النظريات و الدر اسات تمت حول ردود الفعل المختلفة

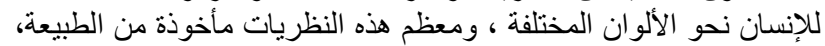

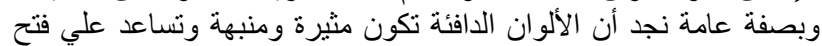

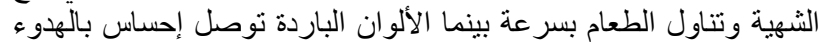

\section{1-4-1 الميول الأتية والإستجابة اللونية لتفضيل الألوان [10] :}

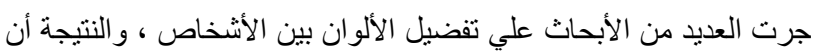

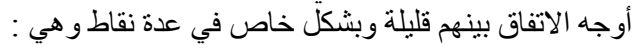

$$
\begin{aligned}
& \text { الثيوع النسبي للألوان المشرقة وغير المشرقة . } \\
& \text { الإختلاف في تفضيل الألوان بين الجنسين . } \\
& \text { الترتيب العام بتفضيل الألو ان }
\end{aligned}
$$

وكانت نتيجة الإختبار ات و التجارب أنه يوجد قدر معين من الاتفاق بين الناس التاس

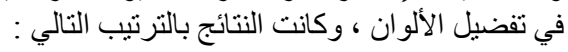

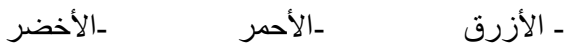

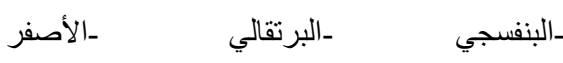

2-4-1 تفضيل الألوان بالنسبة للأطفال (10):

للون إغر اء وجذب خاص لإي جميع الأطفال ، وقام عدد من الباحثين بالعديد

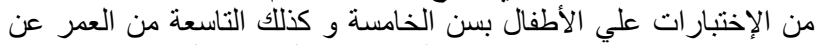



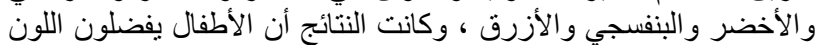

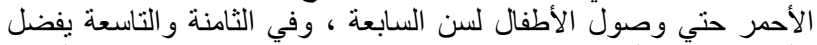
الأطفال اللون الأزرق ـ و عند استعمال نظرية المر الحل الزية الزمنية لنمو النية الأطفال

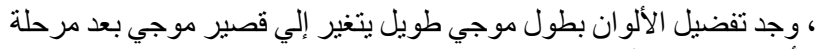

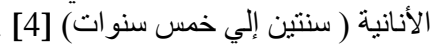

3-4-1 أثر استخدام اللون جماليا

التباين اللوني :

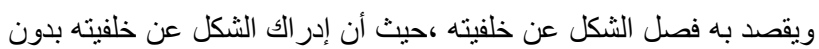

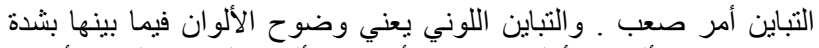

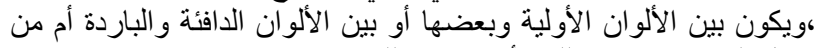

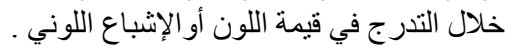
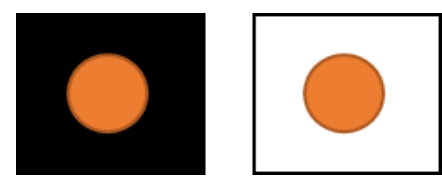

$$
\text { شكل (24) التباين اللوني }
$$

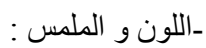

من الرغم أن الملمس ليس من الخواص اللونية ولكنه يؤثر علي انعكاس

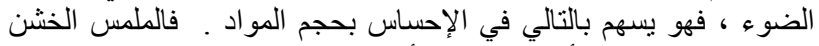

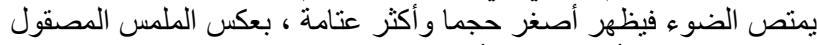

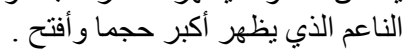

واختيار الملمس يخضع لقواعد الإتزان والتباين ، فنجد ان الملمس الغير

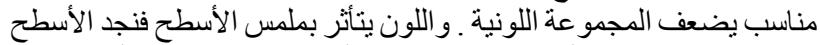





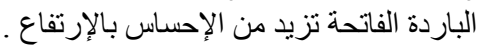

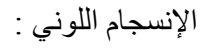

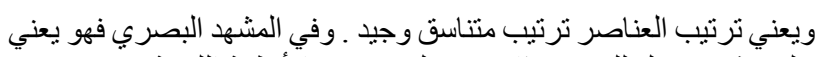

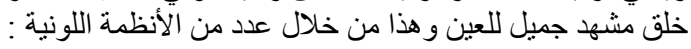

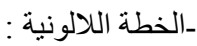

يستخدم اللونين الأبيض و الأسود و التدرجات بينهم .

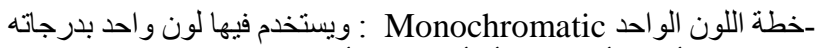
مضاف إليه أبيض أو رمادي أو أسود،وهو أقل المخططات حيوية . 


\begin{tabular}{|c|c|c|}
\hline duetdesigngroup & $\begin{array}{r}\text { Phenomena Studio } \\
-\quad \text { Hisham Alaa } \\
\text { Designs }\end{array}$ & الشركة \\
\hline العامة & العامة & أنواع \\
\hline المباشرة & الغير المباشرة -ـمباشرة & أسلوباء \\
\hline كعنصر الرئيسي طلي طاولة الطعام & الطعام كعنصر الرئيسي علي ل & 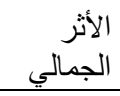 \\
\hline تجنب الإبهار و الوهج الضوئي & 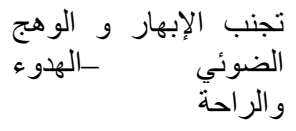 & النفي \\
\hline
\end{tabular}

2-2 التحليل اللوني لصالة طعام:

جدول (3) مقارنة بين التصميم اللوني لصالة طعام بالنموذج المحلي وصالة طعام بالنموذج العالمي

\begin{tabular}{|c|c|c|}
\hline العالمي الطعام بالنموذج & صلالة الطعام بالنموذج & وجه المقارنة \\
\hline البني الفاتح و البني & 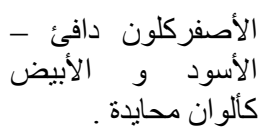 & المستخدمة \\
\hline الأبيض & الأبيض. & لون المستخدم الضوء \\
\hline والثقلام و و الر احة الثهية والدفء & الإحساس بالود و والثقة & الأثر النفسي \\
\hline الإنسجام اللوني & التباين اللوني & الأثر الجمالي \\
\hline
\end{tabular}

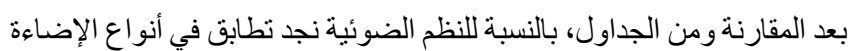

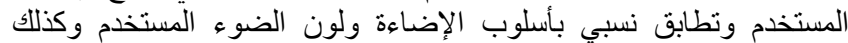

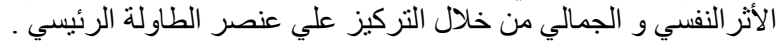

وبالنسبة للنظم اللونية نجد اختلاف بالألوان المستخدمة لإختلاف المساحة

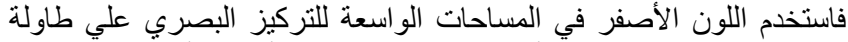
الطعام و إضفاء الإحساس بالألفة بالمكان و ابتعد عن الألوان الألئ الأولية في المساحة

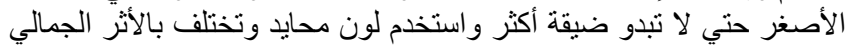
تبعا للتصميم الداخلي ل تبني

\section{3-2 التحليل الضوئي لغرفة النوم الرئيسية}

غرفة النوم هي أكثر الفراغات خصوصية بالبيت ، وتتم فيها الأنشطة بشكل

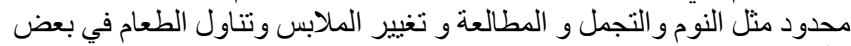

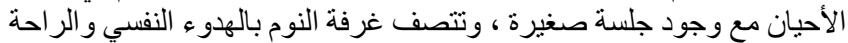

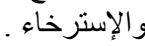

جدول (1) التأثير ات السلبية و الإيجابية علي النفس .

\begin{tabular}{|c|c|c|}
\hline تأثير سلبي & تأثير إيجابي & 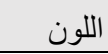 \\
\hline الخوف، الإكتئاب الخشابة & والتفاؤل و الثقة و الطاقة & الأصفر \\
\hline 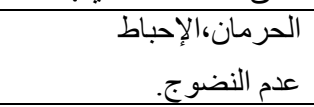 & 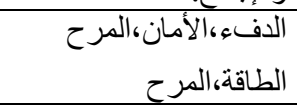 & البرتقالي \\
\hline الدونية و التوحد. & ، الإحتو اءة،الوعي الروحي & البنفسجي \\
\hline الركود و الوهن و البرود & والتناغم،المحبة، الر احة & الأخضر \\
\hline الحزن و انعدام التقة & الأزرق.يدوقد يحل محل & الرمادي \\
\hline البرودة و الثقل و الخطر. & الرقي و الفخامة و الأمن & الأسود \\
\hline عدم الودية و البرودة & والنظافة ح و البساطة و النقاء & الأبيض \\
\hline قلة المر ح و الإكتئاب (21) . & الثقة و الجدية و الدفء & 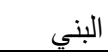 \\
\hline
\end{tabular}

2. الإطار التحليلي

تم اختبار عدد 12 حالة دراسية محلية وعالمية للإطلاع علي المنظومة اللونية و النظام الضوئي المستخدمة واستنتاج الألوان المستخدمة بكل فرلة فراغ والنظام

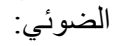
مبررات اختيار النماذج المحلية و العالمية : - ت تنوع بالتة الألوان وأساليب الإضاءة المستخدمة بكل فراغ

$$
\text { سكني. }
$$

- مت - متوع الأنشطة في الفر اغات السكنية.

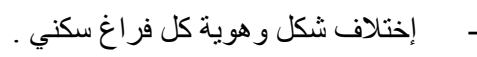
- - إختلاف بيئة و مكان كل فراغ سكني .

\section{1-2 التحليل الضوئي لصالة طعام:}

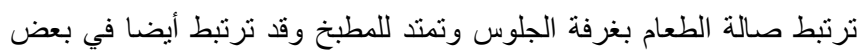

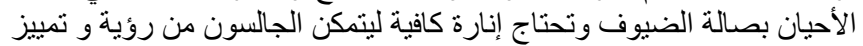

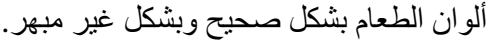

جدول (2) مقارنة بين التصميم الضوئي لصالة طعام بالنموذج المحلي وصالة طعام بالنموذج العالمي مقانة

\begin{tabular}{|c|c|c|}
\hline صالة الطعام بالنموذج العالمي & المحلي الطعام بالنموذج & المقارنة \\
\hline شكل (28) & 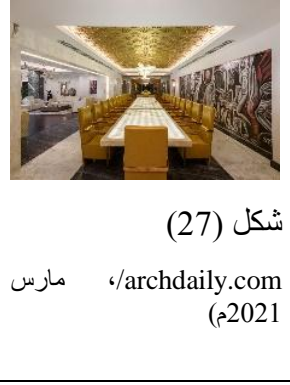 & توضيحية \\
\hline 3*3 منر & 16*5.5 متر & التقريبية \\
\hline
\end{tabular}


5-2 - 5 التحيل الضوئي للحمام: بتميز فراغ الحمام بأن نشاطاته تتميز بأنها خاصة بشخص و احد ، و لا يوجد مجال لممارسة أكثر من نشاط في وقت ونت واحد. جدول (6) مقارنة بين التصميم الضوئي بغرفة النوم الرئيسية في المثنال المحلي وغرفة النوم الرئيسية في المثال العالمي

\begin{tabular}{|c|c|c|}
\hline بالنموذج العالمي & بالنموذج المحلي & وجها \\
\hline شكل (32) & شكل) & توضيحية \\
\hline ann & artattack & الثركمة \\
\hline $4 * 3.5$ & 3*2متر & التقريبية \\
\hline الموضو عية ــ العامة & الموضو عية ـ العامة & أنواعـاءة \\
\hline الغير مباشرة ـالمباشرة & الغير مبانرة ـالمباشرة & أسلوب \\
\hline عناصر التصيع & عناصر التصيعيع. & الجمالي \\
\hline النفسي. البصرية و الهدوء & النفسي. البصرية و الهدوء & الألثر \\
\hline
\end{tabular}

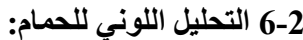

جدول (7) مقارنة بين التصميم اللوني بالحمام في المثال المحلي والحمام في

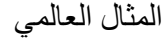

\begin{tabular}{|c|c|c|}
\hline العالميامة محل الدراسة & المحلية محل الدراسة & وجه المقارنة \\
\hline (الألوان المحايدة & الألوان المحايدة & المستخدمة \\
\hline الأبيض & الأبيض. & لون الضوء \\
\hline التباين اللوني & التباين اللوني & الأثر الجمالي \\
\hline و الفظافة و الر احة و الوضوح & والنظافة والراحة & الأثر النفسي \\
\hline
\end{tabular}

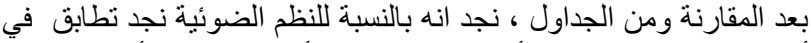

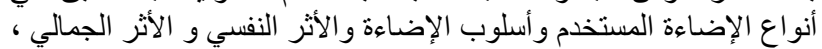



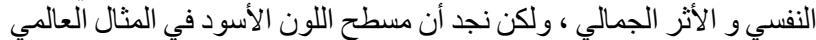

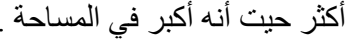

جدول (4) مقارنة بين التصميم الضوئي لغرفة نوم رئيسية بالنموذج المحلي وغرفة نوم رئيسية بالنموذج العالمي

\begin{tabular}{|c|c|c|}
\hline العالمي النوم الرئيسية بالنموذج & غرفة النوم الرئيسية & المقارنة \\
\hline شكل (30) & شكل(29) (2021) & توضيحية \\
\hline ann & $\begin{array}{lr}\text { Phenomena } & \text { Studio - } \\
\text { Hisham } & \text { Alaa } \\
& \text { Designs } \\
\end{array}$ & الشركة \\
\hline 4 4.5*4 & 10 8*ر & التقريبية \\
\hline ـ الموضو عية & ـ الموضو عية & ألنواع \\
\hline الغير مباشرة _المباشرة & الغير مباشرة _المباشرة & أسلوب أل إضاءة \\
\hline للغرقة إظهار & 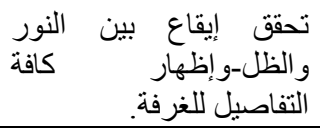 & 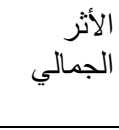 \\
\hline 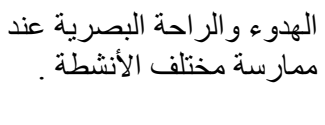 & 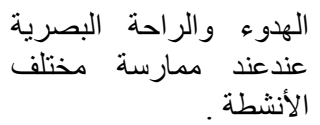 & الالنفي \\
\hline
\end{tabular}

4-2 التحليل اللوني لغرفة النوم الرئيسية

جدول (5) مقارنة بين التصميم اللوني بغرفة النوم الرئيسية في المثال المحلي وغرفة النوم الرئيسية في المثال العالمي لاني

\begin{tabular}{|c|c|c|}
\hline صالعالة الطعام محل الدراسة & صالة الطعام - - محل & وجه المقارنة \\
\hline البني الفاتح و البني & $\begin{array}{r}\text { (ألبني الفاتح و البني } \\
\text { (أل محايدة) }\end{array}$ & المستخدمة \\
\hline الأبيض المصفر & الأصفر - المصبض & الونتخدم الضوء \\
\hline الإنسجام اللوني & الإنسجام اللوني & الأثر الجمالي \\
\hline والدفلام والراحة و والثقة & الجدية، الثقة،الدفء. & الأثر النفسي \\
\hline
\end{tabular}



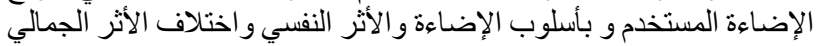
تبعا للتصميم الاعة

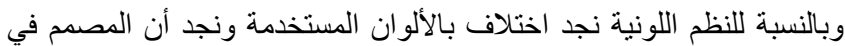

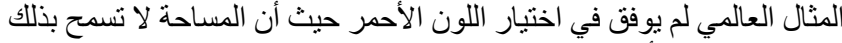

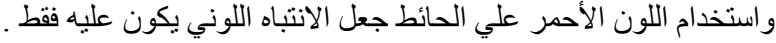




\begin{tabular}{|r|r|r|}
\hline الأثر الجمالي & \\
& الإنسجام اللوني اللإنسجام اللوني & \\
\hline
\end{tabular}

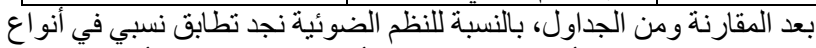

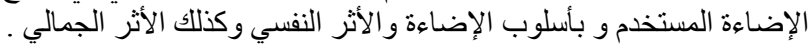

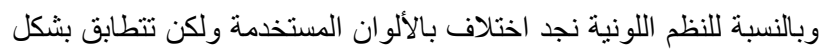

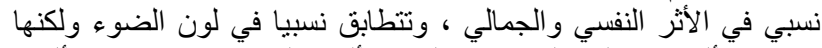

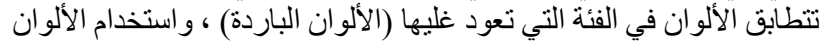

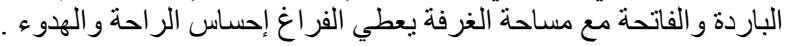

\section{3 النموذج التطبيقي :}

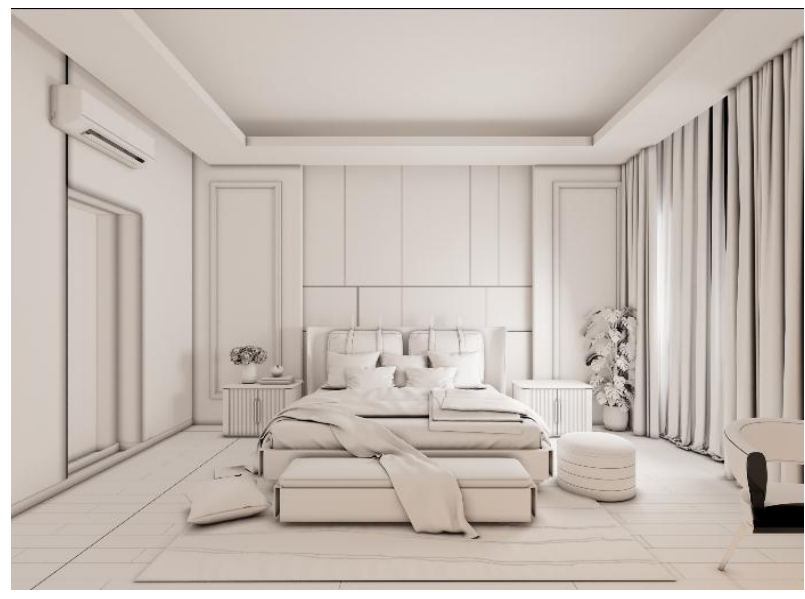

شكل (35) غرفة النوم قبل التصميم اللوني و الضوئي المساحة التقريبية : 4.5*6 منر .

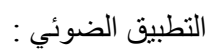

أنواع وأسلوب الإضـاءة المستخدمة : (العامة_الموضو عية)

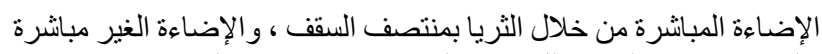

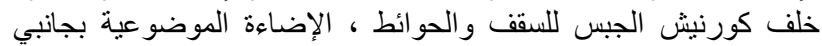

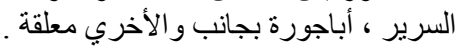

أسلوب الإضاعة : ( مباشر - غير مباشر ) .

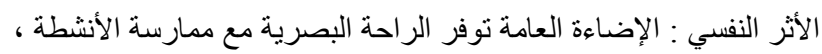

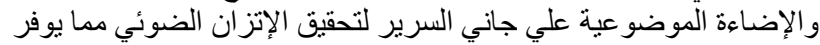

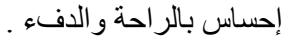

الأثر الجمالي : - التأكيد علي السرير كعنصر أساسي للتصميم . التباين بين الأسطح النصف لامعة و اللامعة . التصميمية تأكيد خطوط السقف دافئة تعكس شعور اً بالألفة و الود .

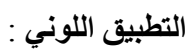
الألوان الرئيسية : البني وتم اختياره للأرضيات و الفرش ، البيج الفاتح و الأبيض للحوان الرئط : لون الضوء : أبيض مصفر

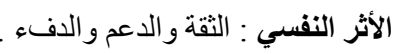

الأثر الجمالي : تحقيق التجانس اللوني عن طريق استخدام خطة الألوان

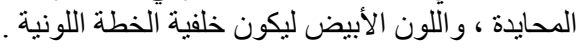

7-2 التحليل الضوئي لغرفة الأطفال:

غرفة نوم الأطفال هي من أكثر فر اغات المسكن أهمية بالنسبة للطفل واسرته

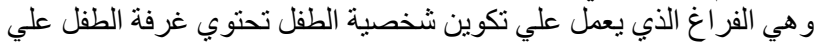

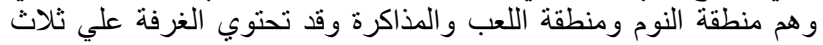
مناطق معا او اثنين.

جدول (8) مقارنة بين التصميم الضوئي بغرفة أطفال في المثال المحلي

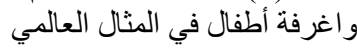

\begin{tabular}{|c|c|c|}
\hline غرفة الأطفال بالنموذج & غرفة الأطفال & المقارنة \\
\hline $\begin{array}{r}\text { شكل (34) } \\
\text { /https://ann1.net } \\
\end{array}$ & شكل(33)ش & توضيحية \\
\hline Dezignark & $\begin{array}{r}\text { Art Attack Interior } \\
\text { Design }\end{array}$ & الثم كة \\
\hline 3*3.5 متر & 3.5*3متر & التقريبية \\
\hline الموضو عية ـ العامة & الزاوية & أنواعـاءة \\
\hline المباشرة & تأكبد الخطر طب التصمبمة ـالمباشرة & 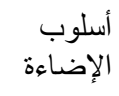 \\
\hline تأكيد الخطوط التصميمية & & 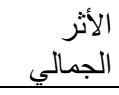 \\
\hline النفسي. البصرية و الهدوء & الر احة البصرية و الهدوء & الألفر \\
\hline
\end{tabular}

8-2 التحليل اللوني لغرفة أطفال

جدول (9) مقارنة بين التصميم اللوني بغرفة أطفال في المثال المحلي وغرفة



\begin{tabular}{|c|c|c|}
\hline غرفة الأطفال & غرفة الأطفال بالنموذج & وجه المقارنة \\
\hline الأزرق (لون بارد) & 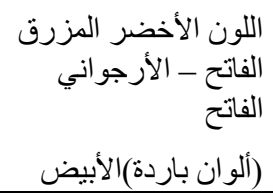 & المستخدمة \\
\hline الأبيض & الأبيض. & لون الضوء \\
\hline والتقة و الر احة و الهدوء & 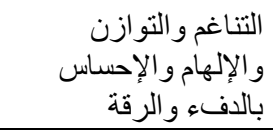 & الأثر النفسي \\
\hline
\end{tabular}






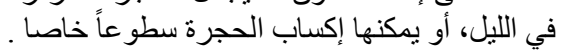

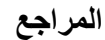

البياني ، نمير قاسم خلف ـ(2005). ألف باء التصميم الداخلي - العراق-

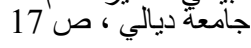

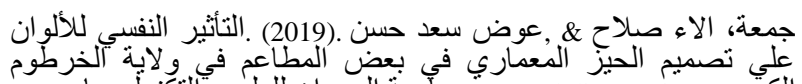
الكبرى , (Doctoral dissertation, آمعة السودان للعلوم ووالتكنولُوجيا.

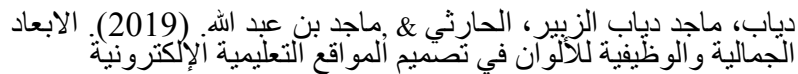

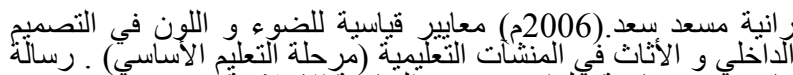

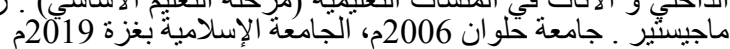

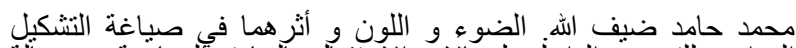

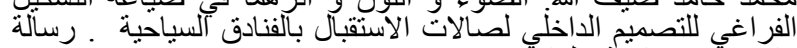

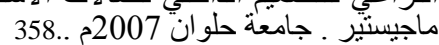

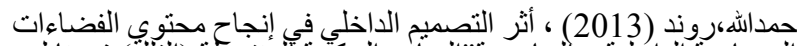

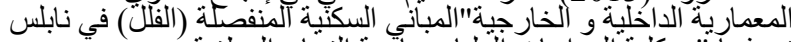

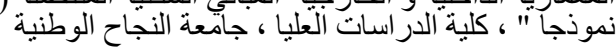

[7] Feisner Anderson " color - how to use color in art and design ", Laurence King publishing Ltd, second edition, 2006.

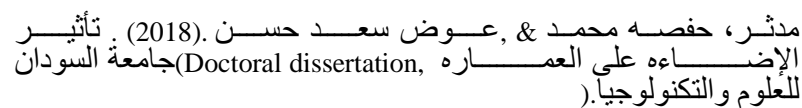

| عميش، رجب عبد الرحمن محمد، معايير و أساسيات الإضـاءة الصناعية

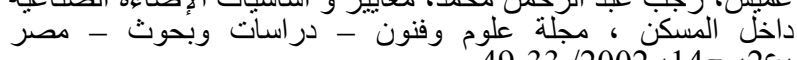

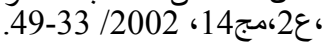

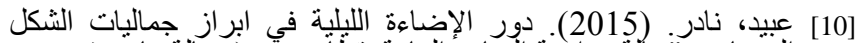

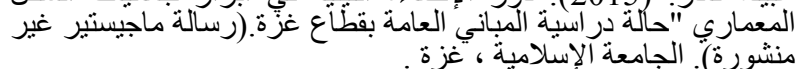

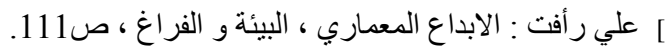

\section{Abstract}

- The color and light between them is a strong correlation that is evident through the environment and its elements. They are considered to be among the most important visual elements of their visual energy affecting mental and sensory perception, and the beauty of the interior design is illustrated by its integral elements. The success of interior design depends on the ability of the designer, his knowledge of the principles and fundamentals of color and light design, his choice of ores, the calculation of absorption and reflection factors of ores and colors, and also his knowledge of the factors affecting each of them. The research was concerned with the discussion and study of color and light and their respective characteristics, the analysis of the factors affecting color and light in the interior designs and the criteria for their respective aesthetic and psychological uses, the study of the methods and types of lighting units, and the use of different sources of lighting. The research examined the color and light in residential spaces, so that people now spend most of their time in closed spaces, especially residential spaces, and by analysing a number of residential spaces.



: (لنتائُج

1- استخدام الألوان المحايدة أساسي في كل أو معظم التصميمات الداخلية

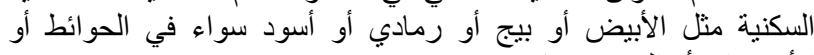

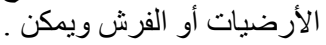

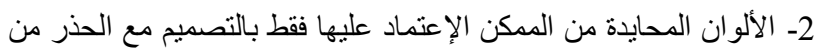

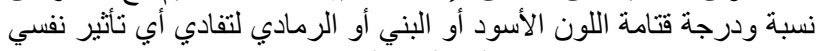

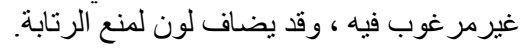

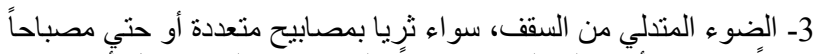

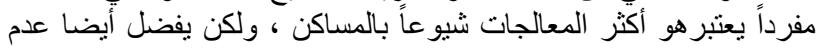

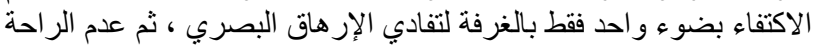

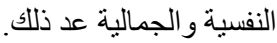



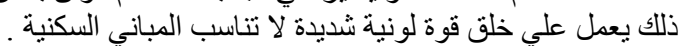

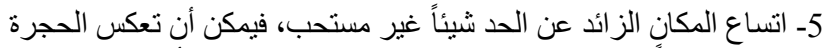

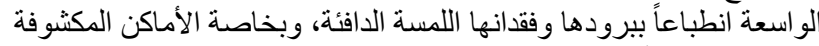

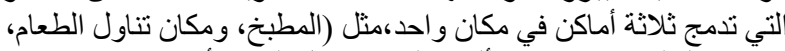

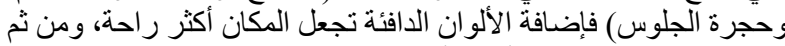

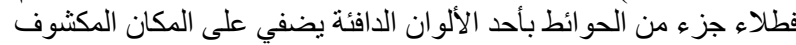
إطلالة دافئة

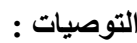

1- استخدام الألوان الباردة (الأزرق - الأخضر - البنفسجي، ....... )

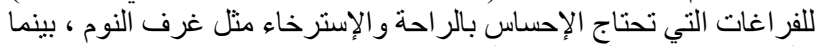

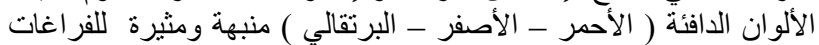

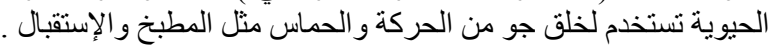

2 ـاختيار الألوان وفقا لكل فراغ و النشاط الداخلي لتأمين المستوي الأفضل

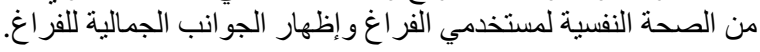

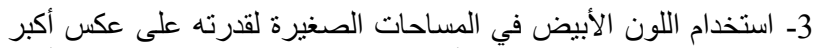
قدر من الإضاءة، فبخلطه مع الألوان الباردة يعطي إحساس بمساحة أكبر الكبر للفراغ.

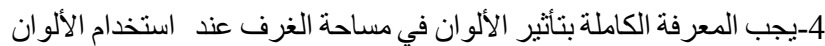

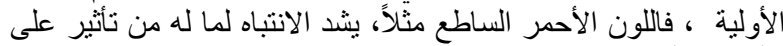

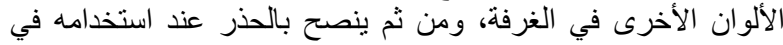

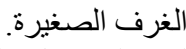

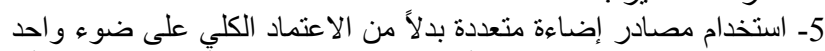
بالسقف. ومصادر الإضاءة أعلى الطاولات لات وفي الأرضيات يمكن أن أن الن 